\title{
Prevalence and prognosis of respiratory pendelluft phenomenon in mechanically ventilated ICU patients with acute respiratory failure: a retrospective cohort study
}

\author{
Yi Chi ${ }^{1}$, Zhanqi Zhao ${ }^{2,3}$, Inéz Frerichs ${ }^{4}$, Yun Long ${ }^{1 *} \mathbb{D}$ and Huaiwu He $\mathrm{1}^{1^{*}}$
}

\begin{abstract}
Background: Respiratory pendelluft phenomenon, defined as intrapulmonary gas redistribution caused by asynchronous alveolar ventilation, could be potentially harmful by inducing lung injury. The aim of the present study was to investigate its prevalence and prognosis in intensive care unit (ICU) patients with acute respiratory failure (ARF).

Methods: This was a retrospective observational study on 200 mechanically ventilated ARF patients treated in a tertiary ICU. The presence of pendelluft was determined using electrical impedance tomography (EIT) within $48 \mathrm{~h}$ after admission. Its amplitude was defined as the impedance difference between the sum of all regional tidal impedance variation and the global tidal impedance variation. A value above 2.5\% (the 95th percentile from 30 healthy volunteers) was considered confirmative for its occurrence.

Results: Pendelluft was found in 61 patients (39 in 94 patients with spontaneous breathing, 22 in 106 receiving controlled ventilation), with an overall prevalence of $31 \%$. Existence of spontaneous breathing and higher global inhomogeneity index were associated with pendelluft. Patients with pendelluft had a longer ICU length of stay [10 (6, 14) vs. $7(4,11)$ days; median (lower, upper quartile); $p=0.022]$ and shorter 14 -day ventilator-free days $[8(1,10)$ vs. 10 $(6,12)$ days; $p=0.015]$. Subgroup survival analysis suggested the association between pendelluft and longer ventilation duration, which was significant only in patients with $\mathrm{PaO}_{2} / \mathrm{FiO}_{2}$ ratio below $200 \mathrm{mmHg}$ (log-rank $p=0.042$ ). ICU mortality did not differ between the patients with and without pendelluft.

Conclusions: Respiratory pendelluft occurred often in our study group and it was associated with longer ventilation duration. Early recognition of this phenomenon should trigger interventions aimed at alleviating pendelluft.
\end{abstract}

Keywords: Pendelluft, Mechanical ventilation, Acute respiratory failure, Intensive care unit

\section{Introduction}

Respiratory pendelluft is the phenomenon of intrapulmonary gas redistribution caused by asynchronous alveolar ventilation. It has been spotted in patients with flail

\footnotetext{
*Correspondence: iculong_yun@163.com; hehuaiwu@pumch.cn 1 State Key Laboratory of Complex Severe and Rare Disease, Department of Critical Care Medicine, Peking Union Medical College Hospital, Peking Union Medical College, Chinese Academy of Medical Sciences, 1 shuaifuyuan, Dongcheng District, Beijing, China

Full list of author information is available at the end of the article
}

chest [1], obstructive lung disease [2], and acute respiratory distress syndrome (ARDS) [3]. Evidence from animal experiments has suggested that pendelluft could be potentially harmful by inducing local overdistension and tidal recruitment [4-6]. Hence, the early recognition of pendelluft is warranted for timely adjustment of treatment and ventilation strategy, especially in critically ill patients. Earlier techniques (positron imaging, multichannel lung sound analysis, darkfield microscopy, etc.) 
used to monitor pendelluft are not suitable for critically ill patients.

The chest electrical impedance tomography (EIT) is a non-invasive monitoring technique that can obtain realtime images of regional lung ventilation at the bedside by detecting the bio-impedance changes during consecutive respiratory cycles [7]. The application of EIT has enabled bedside detection of respiratory pendelluft in patients in the intensive care unit (ICU). It allows not only qualitative, but also quantitative analysis of pendelluft $[8,9]$. Despite the progress, little is known about the epidemiology of pendelluft and its association with clinical outcome.

The primary objective of this retrospective study was to explore the prevalence and prognosis of pendelluft in mechanically ventilated ICU patients with acute respiratory failure (ARF).

\section{Methods}

From January 2020 to November 2021, ICU patients with ARF, defined by the ratio of partial pressure of arterial oxygen to fraction of inspired oxygen $\left(\mathrm{PaO}_{2} / \mathrm{FiO}_{2}\right)$ below $300 \mathrm{mmHg}$ within $48 \mathrm{~h}$ of admission, and receiving mechanical ventilation were eligible for study inclusion. The exclusion criteria were: age $<18$ years, pregnancy, body mass index over $50 \mathrm{~kg} / \mathrm{m}^{2}$, ribcage malformation, and any contraindication to the use of EIT (automatic implantable cardioverter defibrillator, chest wounds limiting electrode belt placement, implantable pumps, etc.). This retrospective study was approved by the Institutional Research and Ethics Committee of Peking Union Medical College Hospital (S-K1859).

The following parameters were documented: age, sex, predicted body weight (PBW), Acute Physiology and Chronic Health Evaluation II (APACHE II) score, arterial blood gas and respiratory parameters at the time point of EIT recording [tidal volume, respiratory rate, positive end-expiratory pressure (PEEP), existence of spontaneous breathing (defined as EIT-based respiratory rate higher than set respiratory rate under controlled ventilation)], ventilatory ratio (minute ventilation $\left.[\mathrm{mL} / \mathrm{min}] \times \mathrm{PaCO}_{2} \quad[\mathrm{mmHg}]\right) /(\mathrm{PBW} \quad[\mathrm{kg}] \times 100 \quad[\mathrm{~mL} /$ $\mathrm{min}] \times 37.5[\mathrm{mmHg}])[10]$, outcome measures such as ICU length of stay, 14-day ventilator-free days (VFD) and ICU mortality.

\section{EIT-based measurements}

EIT measurements were performed within $24 \mathrm{~h}$ of proven ARF diagnosis with PulmoVista 500 (Dräger Medical, Lübeck, Germany). An EIT belt with 16 electrodes was placed around the patient's thorax at the 4-5th intercostal space level. EIT measures changes in voltages between electrode pairs, reconstructs the impedance changes within the measurement plane and then calculates the regional ventilation map by subtracting the inspirationbegin from the expiration-begin image as well as the global tidal signal variation.

To establish a reference value, EIT measurements were performed in 30 healthy volunteers without any underlying lung disease (demographics are summarized in Additional file 1: Table S1). The following EIT-based parameters were calculated in both patients and healthy subjects:

\section{Pendelluft}

A recent published EIT-based algorithm for pendelluft detection [9] was adopted by our study. According to the theory of pendelluft proposed by Otis et al. [11], when pendelluft occurs, the sum of the regional tidal volumes is greater than the overall tidal volume, their difference representing the pendelluft volume. Similarly, the EIT-based pendelluft amplitude was defined as the impedance difference between the sum of all regional tidal impedance variation (TIV) and the global TIV (Additional file 1: Fig. S1). Since this pixel-based algorithm is so sensitive, the occurrence of pendelluft was considered only when its amplitude exceeded $2.5 \%$ of global TIV (which was the 95th percentile from 30 healthy volunteers) (Additional file 1: Table S1).

\section{Ventilation defect score}

Its calculation was based on a semi-quantitative method for analyzing heterogeneity of ventilation distribution validated by a previous study [12]. The global ventilation map was separated into four non-overlapping quadrants of equal size to trace gas distribution into different regions of interest (ROIs): lower left (LL), lower right (LR), upper left (UL) and upper right (UR). Distribution defects in each quadrant were scored as follows: 0 (quadrant distribution\% $\geq 15 \%), 1 \quad(15 \%>$ quadrant distribution $\% \geq 10 \%$ ) and 2 (quadrant distribution $\%<10 \%$ ). The total ventilation defect score was the sum of the scores of each quadrant (Additional file 1: Fig. S2).

\section{Global inhomogeneity (GI) index}

The GI index was designed to describe the overall degree of spatial heterogeneity of ventilation [13]. A smaller global inhomogeneity index represents a more homogeneous distribution.

\section{Statistical analysis}

Descriptive data are expressed as numbers and percentages for categorical variables and median (lower, upper quartile) for continuous variables. Categorical variables were compared using the Pearson Chisquare test, whereas continuous variables distributed 
nonparametrically between groups were compared using the Mann-Whitney $U$ test. Pendelluft amplitudes among groups of different defect scores were compared using the Kruskal-Wallis $H$ test.

To evaluate independent factors associated with pendelluft, significant univariate risk factors or variables considered clinically relevant to pendelluft were examined using backward stepwise multivariable logistic regression analysis. To avoid overfitting, a maximal number of six variables in the pendelluft model was entered in view of the 61 events observed (APACHE II score, $\mathrm{PaO}_{2} / \mathrm{FiO}_{2}$ ratio, PEEP, spontaneous breathing, respiratory rate and GI index). The linear relationship of PEEP and pendelluft amplitude was explored with Spearman correlation coefficient. To analyze the relationship between pendelluft and ventilation duration, cause-specific Cox proportional hazard models were implemented to predict the relative hazard of successful discontinuation from ventilator with 95\% confidence intervals; the model was adjusted for APACHE II score and $\mathrm{PaO}_{2} / \mathrm{FiO}_{2}$ ratio. Restricted cubic spline was used to explore the possible nonlinear relationship between pendelluft amplitude and the relative hazard of discontinuation from ventilator. $P$ values of less than 0.05 were considered statistically significant. Statistical analyses were performed using SPSS 25.0 (SPSS, Chicago, IL) and R version 4.0.3.

\section{Results}

\section{Risk factors for pendelluft}

A total of 200 patients (135 men and 65 women) were included, with a median age of 62 years and a median APACHE II score of 16 at $24 \mathrm{~h}$ of ICU admission. Patients received mechanical ventilation with a median $\mathrm{PaO}_{2} / \mathrm{FiO}_{2}$ ratio of $200(164,246) \mathrm{mmHg}$, tidal volume of $428(396,501) \mathrm{mL}, \mathrm{PEEP}$ of $7(5,8) \mathrm{cmH}_{2} \mathrm{O}$, and respiratory rate of $17(15,19)$ cycles/minute at the time point of EIT recording (Table 1). 94 (47\%) of them had spontaneous breathing. Pendelluft was detected in 61 of the 200 ARF patients (prevalence of $31 \%$ ), 39 of 94 spontaneously breathing patients (41\%) and 22 of 106 patients receiving fully controlled ventilation (21\%). Patients with pendelluft had a higher proportion of spontaneous breathing, respiratory rate and higher GI index (Table 1). Tidal volume, PEEP, $\mathrm{PaCO}_{2}$ and ventilatory ratio did not differ between the groups. Multivariable logistic regression analysis identified that the existence of spontaneous breathing and higher GI index were associated with pendelluft (Table 2). The relationship between PEEP and pendelluft amplitude was explored in one subgroup of patients with $\mathrm{P} / \mathrm{F}$ ratio below $150 \mathrm{mmHg}$ (39 patients; Spearman $\mathrm{r}=-0.37, p=0.02$ ) and the other subgroup of spontaneous breathing patients (94 patients; Spearman $\mathrm{r}=-0.22, p=0.03$ ) (Fig. 1).
Higher proportion of higher ventilation defect score was seen in patients with pendelluft $(p=0.042)$. Patients with higher defect score also had larger pendelluft amplitude $[1.2(0.5,2.5)$ versus $1.5(0.7,3.8)$ versus $2.1(0.9$, 6.8 ) in \% of global TIV for defect score $0,1, \geq 2$, respectively; Kruskal-Wallis $p=0.011$ ] (Additional file 1: Fig. S3). Subsequent multiple comparisons showed the difference was significant only between defect score 0 and $\geq 2$ $(p=0.008)$.

\section{Outcome}

The outcome of patients with or without pendelluft is displayed in Tables 1 and 3 and Figs. 2 and 3. ICU mortality was $12 \%$ for the whole study population and did not differ between the groups $(p=0.151)$. ICU length of stay was longer $[10(6,14)$ versus $7(4,11)$ days; $p=0.022]$ and 14 -day ventilator-free days was shorter $[8(1,10)$ versus $10(6,12)$ days; $p=0.015$ ] in patients with pendelluft. Survival analysis revealed marginally non-significant effect of pendelluft on discontinuation from ventilation within 14 days in the overall study population (log-rank $p=0.066)$. When the study population was divided into two subgroups according to $\mathrm{PaO}_{2} / \mathrm{FiO}_{2}$ ratio, pendelluft was associated with significantly longer 14-day ventilation duration in patients with $\mathrm{PaO}_{2} / \mathrm{FiO}_{2}$ ratio below $200 \mathrm{mmHg}(\log$-rank $p=0.042)$ while it had no effect on 14-day ventilation duration in patients with $\mathrm{PaO}_{2} /$ $\mathrm{FiO}_{2}$ ratio above $200 \mathrm{mmHg}(\log$-rank $p=0.930$ ). Cox regression also identified pendelluft as an independent risk factor for longer 14-day ventilation duration, after being adjusted by APACHE II score and $\mathrm{PaO}_{2} / \mathrm{FiO}_{2}$ ratio (Table 3). Higher pendelluft amplitude was associated with lower likelihood of discontinuing from mechanical ventilation within 14 days, taken pendelluft amplitude $2.5 \%$ as a reference (Fig. 3).

Outcome analyses were also performed in patients with and without spontaneous breathing separately (Additional file 1: Fig. S4). In either group, pendelluft was not associated with longer 14-day ventilation duration, but further investigation into patients with spontaneous breathing and simultaneously $\mathrm{P} / \mathrm{F}$ ratio below $200 \mathrm{mmHg}$ showed a marginal effect of pendelluft with longer 14-day ventilation duration $(\log \operatorname{rank} p=0.081)$.

\section{Discussion}

The main findings of our study were that: (1) pendelluft was detected in $31 \%$ of 200 ARF patients ventilated in the ICU; (2) higher GI index and the existence of spontaneous breathing were the independent factors associated with pendelluft; (3) pendelluft was associated with longer 14-day ventilation duration among patients with $\mathrm{PaO}_{2} /$ $\mathrm{FiO}_{2}$ ratio below $200 \mathrm{mmHg}$. 
Table 1 Clinical characteristics and outcomes of patients having acute respiratory failure with or without pendelluft

\begin{tabular}{|c|c|c|c|c|}
\hline & $\begin{array}{l}\text { All patients } \\
(n=200)\end{array}$ & $\begin{array}{l}\text { No pendelluft } \\
(n=139)\end{array}$ & $\begin{array}{l}\text { Pendelluft } \\
(n=61)\end{array}$ & $p$ value \\
\hline Age, years & $62(51,69)$ & $62(51,68)$ & $62(50,73)$ & 0.549 \\
\hline Female gender, $n(\%)$ & $65(32 \%)$ & $44(32 \%)$ & $21(34 \%)$ & 0.825 \\
\hline Predicted body weight, kg & $64.0(56.2,68.5)$ & $64.0(54.1,68.5)$ & $64.9(56.8,69.4)$ & 0.290 \\
\hline APACHE II score & $16(13,20)$ & $16(13,20)$ & $17(14,23)$ & 0.153 \\
\hline \multicolumn{5}{|l|}{ Respiratory parameters } \\
\hline Spontaneous breathing, $n$ (\%) & $94(47 \%)$ & $55(40 \%)$ & $39(64 \%)$ & 0.002 \\
\hline Tidal volume, $\mathrm{mL}$ & $428(396,501)$ & $430(398,500)$ & $421(390,510)$ & 0.810 \\
\hline Respiratory rate, minute ${ }^{-1}$ & $17(15,19)$ & $16(15,18)$ & $18(16,21)$ & 0.002 \\
\hline PEEP, $\mathrm{cmH}_{2} \mathrm{O}$ & $7(5,8)$ & $7(5,8)$ & $6(5,8)$ & 0.152 \\
\hline \multicolumn{5}{|l|}{ Arterial blood gas } \\
\hline $\mathrm{PaO}_{2} / \mathrm{FiO}_{2}$ ratio, $\mathrm{mmHg}$ & $200(164,246)$ & $204(167,249)$ & $194(151,239)$ & 0.225 \\
\hline $\mathrm{pH}$ & $7.4(7.4,7.5)$ & $7.4(7.4,7.5)$ & $7.4(7.4,7.5)$ & 0.763 \\
\hline $\mathrm{PaCO}_{2}, \mathrm{mmHg}$ & $40.8(37.0,43.9)$ & $41.0(37.6,44.0)$ & $39.4(36.0,42.4)$ & 0.189 \\
\hline Ventilatory ratio & $1.3(1.2,1.5)$ & $1.3(1.2,1.5)$ & $1.4(1.2,1.6)$ & 0.170 \\
\hline \multicolumn{5}{|l|}{ EIT parameters } \\
\hline Dorsal ventilation, $\%$ & $41(32,47)$ & $41(32,48)$ & $41(32,47)$ & 0.984 \\
\hline Defect Score, $n(\%)$ & & & & 0.042 \\
\hline 0 & $88(44 \%)$ & $68(49 \%)$ & $20(33 \%)$ & \\
\hline 1 & $61(30 \%)$ & $42(30 \%)$ & $19(31 \%)$ & \\
\hline$\geq 2$ & $51(26 \%)$ & $29(21 \%)$ & $22(36 \%)$ & \\
\hline Gl index & $0.36(0.34,0.38)$ & $0.36(0.34,0.37)$ & $0.37(0.34,0.39)$ & 0.023 \\
\hline Pendelluft amplitude, \% & $1.4(0.7,3.5)$ & $0.9(0.5,1.6)$ & $6.4(3.9,13.3)$ & $<0.001$ \\
\hline \multicolumn{5}{|l|}{ Outcome } \\
\hline MV duration, days & $5(3,8)$ & $4(2,7)$ & $6(3,8)$ & 0.052 \\
\hline ICU length of stay, days & $7(5,13)$ & $7(4,11)$ & $10(6,14)$ & 0.022 \\
\hline 14-day ventilator-free days & $9(5,11)$ & $10(6,12)$ & $8(1,10)$ & 0.015 \\
\hline ICU mortality, n (\%) & $23(12 \%)$ & $13(9 \%)$ & $10(16 \%)$ & 0.151 \\
\hline
\end{tabular}

Data are presented as median (lower, upper quartile) unless otherwise specified

APACHE Acute Physiology and Chronic Health Evaluation, PEEP positive end-expiratory pressure, EIT electrical impedance tomography, GI global inhomogeneity, MV mechanical ventilation, ICU intensive care unit

Table 2 Univariate and multivariate logistic regression analysis for pendelluft

\begin{tabular}{|c|c|c|c|c|}
\hline \multirow[t]{2}{*}{ Variables } & \multicolumn{2}{|c|}{ Univariate logistic regression } & \multicolumn{2}{|c|}{ Multivariate logistic regression } \\
\hline & Odds ratio $(95 \% \mathrm{Cl})$ & $p$ & Odds ratio $(95 \% \mathrm{Cl})$ & $p$ \\
\hline APACHE II score & $1.043(0.994-1.096)$ & 0.086 & $1.053(0.999-1.111)$ & 0.052 \\
\hline $\mathrm{PaO}_{2} / \mathrm{FiO}_{2}$ ratio & $0.997(0.991-1.002)$ & 0.211 & $0.995(0.989-1.002)$ & 0.164 \\
\hline PEEP & $0.930(0.792-1.082)$ & 0.357 & $0.944(0.789-1.123)$ & 0.520 \\
\hline Spontaneous breathing & $2.707(1.463-5.112)$ & 0.002 & $2.375(1.175-4.883)$ & 0.017 \\
\hline Respiratory rate & $1.133(1.044-1.235)$ & 0.003 & $1.070(0.975-1.178)$ & 0.157 \\
\hline Gl index (per 0.01 increase) & $1.153(1.049-1.275)$ & 0.004 & $1.141(1.030-1.272)$ & 0.014 \\
\hline
\end{tabular}

APACHE Acute Physiology and Chronic Health Evaluation, PEEP positive end-expiratory pressure; Gl global inhomogeneity

\section{Definition and prevalence of pendelluft}

Since the first report of "occult pendelluft" phenomenon in anesthetized pigs with acute lung injury and a patient with acute respiratory distress syndrome (ARDS) in 2013
[3], EIT has been increasingly used to detect the pendelluft in critically ill patients [14-17]. At least two studies tried to quantitatively assess the gas volume subjected to pendelluft and moving within the lungs through 
a P/F ratio below $150 \mathrm{mmHg}$



b Presence of spontaneous breathing

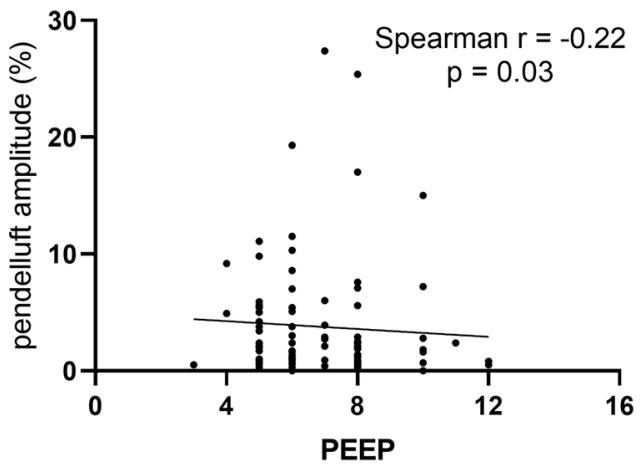

Fig. 1 Exploration of correlation between PEEP and pendelluft amplitude in A P/F ratio below $150 \mathrm{mmHg}$ and $\mathbf{B}$ presence of spontaneous breathing, respectively

Table 3 Univariate and multivariate Cox regression analysis for discontinuation from ventilation at Day 14 among patients with $\mathrm{PaO}_{2} /$ $\mathrm{FiO}_{2}$ ratio $<200 \mathrm{mmHg}$

\begin{tabular}{|c|c|c|c|c|}
\hline \multirow[t]{2}{*}{ Variables } & \multicolumn{2}{|c|}{ Univariate Cox regression } & \multicolumn{2}{|c|}{ Multivariate Cox regression } \\
\hline & Hazard ratio $(95 \% \mathrm{Cl})$ & $p$ & Hazard ratio $(95 \% \mathrm{Cl})$ & $p$ \\
\hline Pendelluft & $0.592(0.354-0.991)$ & 0.046 & $0.562(0.334-0.946)$ & 0.030 \\
\hline APACHE II score & $0.930(0.891-0.970)$ & 0.001 & $0.922(0.882-0.964)$ & $<0.001$ \\
\hline $\mathrm{PaO}_{2} / \mathrm{FiO}_{2}$ ratio & $1.008(1.002-1.015)$ & 0.016 & $1.009(1.002-1.016)$ & 0.015 \\
\hline PEEP & $1.020(0.980-1.122)$ & 0.684 & Not included & \\
\hline
\end{tabular}

APACHE Acute Physiology and Chronic Health Evaluation, PEEP positive end-expiratory pressure, $\mathrm{PaO}_{2}$ arterial partial pressure of oxygen, $\mathrm{FiO}_{2}$ fraction of inspired oxygen

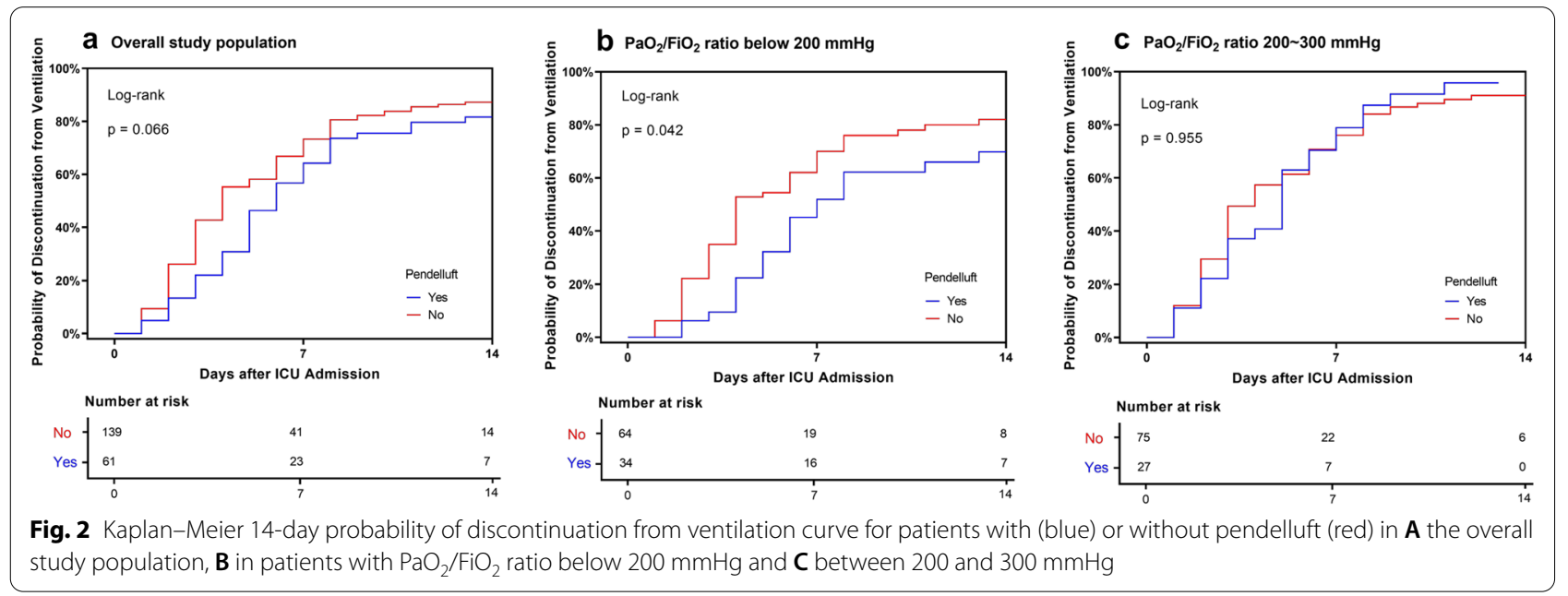

EIT-based algorithms. Coppadoro et al. [8] defined the increased regional impedance from four quadrant ROIs during the global expiratory phase and vice versa as pendelluft. They reported a median pendelluft volume of $3.3(2.1,8.8) \mathrm{mL}$ in 20 patients who had just failed a spontaneous breathing test. Sang et al. [9] introduced a method to detect the amplitude of pendelluft by comparing the sum of all pixel TIV with the global TIV, and expressed it as percent, where $1 \%$ of pendelluft amplitude was equal to $1 \mathrm{~mL}$ pendelluft volume per $100 \mathrm{~mL}$ tidal 


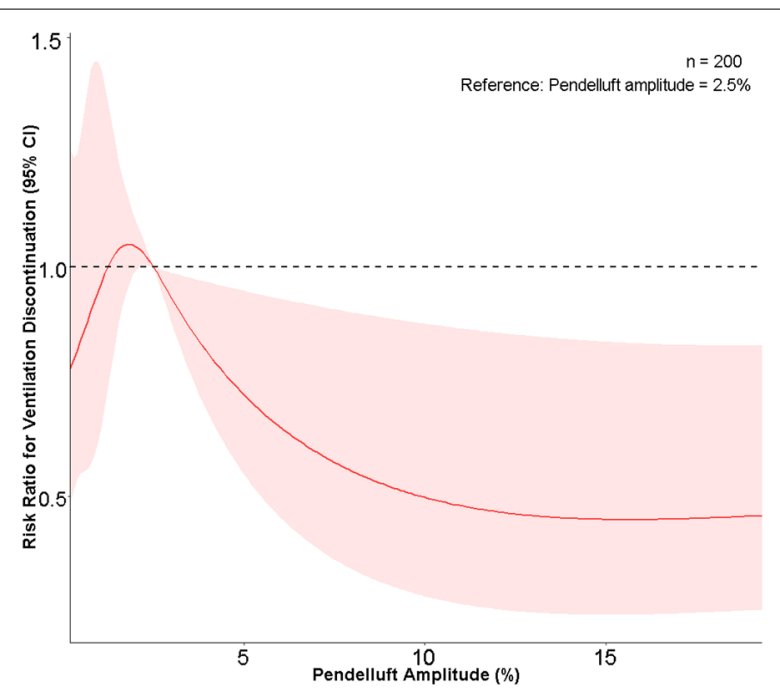

Fig. 3 Relationship between pendelluft amplitude and risk ratio for ventilation discontinuation in the study population. $2.5 \%$ amplitude of pendelluft was set as the reference

volume. The latter algorithm was closer to the original theory of pendelluft proposed by Otis et al. [11] and was adopted in our study. According to Otis et al., pendelluft could occur where heterogeneity of respiratory time constants (compliance * resistance) existed between adjacent alveoli. The time shift due to heterogeneity of time constants within the lungs could be assessed by the present pendelluft evaluation. On the other hand, heterogeneous time constants may also result in a so-called "regional ventilation delay": heterogeneous regional inflation as compared to the global due to collapse of alveoli and/or airways without time shift at the end of inspiration. Such regional ventilation delay was not captured by our calculation. Although the definition of pendelluft was relatively clear, the problem was, the EIT-based algorithm was so sensitive to detect a small amount of pendelluft, possibly without pathological significance, in healthy adults without underlying lung diseases. Therefore, we investigated the pendelluft amplitude in 30 healthy volunteers and then set the 95th percentile, i.e., $2.5 \%$ as a threshold, only above which the occurrence of clinically significant pendelluft was considered. Based on that definition, we were able to report the incidence of pendelluft for the first time among ventilated ICU patients with ARF.

\section{Risk factors for pendelluft}

Respiratory time constants inequality, also interpreted as alveolar heterogeneity, is the basis of respiratory pendelluft. In the present study, we used two easily accessible parameters to describe the lung heterogeneity. One was the ventilation defect score [12], a semi-quantitative parameter to describe the severity of uneven gas distribution to four quadrant ROIs, ranging from 0 to 6 . Higher scores, reflecting higher heterogeneity in gas distribution, were associated with larger amplitudes of pendelluft. The other was the GI index [13], widely used in the evaluation of lung recruitment, PEEP titration and weaning process. The calculation of the GI index was based on the deviation of each pixel tidal impedance variation. Higher GI values denoted higher degree of lung heterogeneity. Our study recognized GI index as an independent factor associated with pendelluft.

Spontaneous breathing effort during mechanical ventilation might improve gas exchange and lung aeration, but excessive effort could also cause uneven distribution of intrathoracic pressure in already injured lung, which was proposed as another mechanism eliciting respiratory pendelluft [3]. Previous studies noticed the disappearance of pendelluft in ARDS patients when neuromuscular blockers were applied $[3,18]$, supporting the association between spontaneous effort and pendelluft. In our study population, pendelluft was more likely to occur in patients with spontaneous breathing, but there was no direct evaluation of breathing effort. Respiratory rate was an indirect indicator reflecting the breathing effort $[19,20]$. It was higher in patients with pendelluft but without statistical significance after multivariable regression. Relatively low respiratory frequency (below 21 cycles/minute in $75 \%$ of spontaneously breathing patients) might obscure its effect. Careful monitoring of spontaneous breathing effort (e.g., P0.1, pressure muscle index, negative deflection of pressure during end-expiratory occlusion, etc.) and its association with pendelluft amplitude is needed. It should be also noted that zero spontaneous effort did not exclude the possibility of pendelluft, as was seen in around $21 \%$ of ARF patients without presence of spontaneous breathing and was proven by dynamic computed tomography in an experimental study conducted on a swine model of mild acute respiratory distress syndrome [18].

Some studies found that applying higher PEEP could alleviate pendelluft in ARDS $[4,5]$. As pendelluft was mainly associated with lung heterogeneity and dynamic pleural pressure variations, higher PEEP may reduce the magnitude of pendelluft by lowering the level of spontaneous effort via neuromechanical uncoupling and by reducing atelectasis. Both mechanisms promote a more homogeneous lung expansion [21]. Opposite evidence also existed showing PEEP had no effect on pendelluft [22], but the ventilation mode, baseline $\mathrm{P} / \mathrm{F}$ ratio and calculation of pendelluft in the study were all different from previous ones. Hence, we made subgroup analysis and found a week 
but significant negative correlation between PEEP and pendelluft amplitude in the more hypoxemic population and patients with spontaneous breathing. The different results among studies could be partly explained by the disease severity and whether spontaneous breathing was present.

\section{Clinical implication and prognosis of pendelluft}

Pendelluft has the potential to cause lung injury as it could increase local lung stress and cause regional overdistension even under protective ventilator settings. Previous animal experiments suggested that pendelluft was associated with tidal recruitment, and that effort-dependent lung injury occurred in the same region where pendelluft appeared [4-6]. Our study revealed for the first time that pendelluft was associated with longer duration of mechanical ventilation among ICU patients with $\mathrm{PaO}_{2} / \mathrm{FiO}_{2}$ ratio below $200 \mathrm{mmHg}$, after APACHE II score and $\mathrm{PaO}_{2} / \mathrm{FiO}_{2}$ ratio was adjusted. The effect of pendelluft on ventilation duration was dependent on the severity of ARF as similar effect was not seen in mild impaired oxygenation. Results from subgroup analysis according to whether spontaneous breathing was present might suggest different clinical impact of pendelluft in active or passive condition (Additional file 1: Fig. S4). We supposed that pendelluft associated with spontaneous effort in patients with moderate-to-severe impaired oxygenation could be an injurious ventilation pattern that possibly lengthen ventilation duration, while pendelluft in passive condition might only imply lung inhomogeneity but no direct evidence to lung injury.

Results from analysis of restricted cubic spline suggested that pendelluft amplitude below the reference of $2.5 \%$ had an unclear influence on the probability of successful discontinuation from mechanical ventilation, while higher amplitude of pendelluft above the threshold was associated with prolonged ventilation duration. The optimal threshold of pendelluft amplitude or volume for predicting clinical outcome warrants further investigation.

We also explored the relationship between pendelluft amplitude and ventilatory ratio, a variable reflecting ventilation efficiency of the lung [10]. A positive correlation was hypothesized because the pendelluft gas moving within the lung was not expected to contribute to gas exchange, possibly resulting in reduction of ventilation efficiency. However, our results did not support the hypothesis. The effect of pendelluft on ventilation efficiency might have been too weak or masked by confounders.

\section{Study limitations}

Our study has some limitations. First, the overall study population was heterogeneous, with both assisted and controlled ventilation. The subjects had only mild-tomoderate impaired oxygenation on average, which might weaken the effect of pendelluft on clinical outcome. That was also the reason why we chose 14-day rather than 28-day ventilator-free day as the primary mechanical ventilation-related outcome. Second, the out-of-phase impedance change generated by diaphragm movement [23] or pleural effusion [24] could be mistaken as pendelluft. Since an upward shift of diaphragm was common in patients with obesity or increased intra-abdominal pressure, electrode belts were placed at a higher position in these patients (3-4th intercostal space) according to their chest X-ray or lung ultrasound findings to avoid the signal interference from the moving diaphragm. Future EIT algorithm needs be updated to distinguish lung regions with present diaphragm movement or pleural effusion. Third, the respiratory management was probably influenced by EIT results in some cases, introducing a potential bias when assessing the impact of pendelluft on patient outcome.

\section{Conclusions}

In conclusion, pendelluft was identified in $31 \%$ of a single-center ARF patients ventilated in the ICU. Pendelluft occurred more often in cases with spontaneous breathing and higher lung heterogeneity. It was associated with longer ventilation duration in patients with $\mathrm{PaO}_{2} / \mathrm{FiO}_{2}$ ratio below $200 \mathrm{mmHg}$. Careful monitoring and therapies aimed at alleviating pendelluft should be tested in patients with severe hypoxia in the future.

\section{Abbreviations}

APACHE: Acute Physiology and Chronic Health Evaluation; ARDS: Acute respiratory distress syndrome; $\mathrm{ARF}$ : Acute respiratory failure; $\mathrm{Cl}$ : Confidence interval; EIT: Electrical impedance tomography; $\mathrm{FiO}_{2}$ : Fraction of inspiratory oxygen; Gl: Global inhomogeneity; ICU: Intensive care unit; LL: Lower left; LR: Lower right; MV: Mechanical ventilation; PBW: Predicted body weight; $\mathrm{PaO}_{2}$ : Partial pressure of arterial oxygen; PEEP: Positive end-expiratory pressure; $\mathrm{ROI}$ : Region of interest; TIV: Tidal impedance variation; UL: Upper left; UR: Upper right; VFD: Ventilator-free day.

\section{Supplementary Information}

The online version contains supplementary material available at https://doi. org/10.1186/s13613-022-00995-w.

Additional file 1: Figure S1. Schematic diagram of EIT-measured pendelluft amplitude. Pixel 1 and 2 are impedance-time curves from two representative pixels with large ventilation shift. The EIT-based pendelluft amplitude is calculated as the impedance difference between the sum of all pixel TIV and the global TIV. TIV, tidal impedance variation. A.U., arbitrary unit. Figure S2. Schematic diagram of ventilation defect score. Figure S3. Relationship between ventilation defect score and pendelluft amplitude. Figure S4. Survival analyses performed in patients with and without 
spontaneous breathing separately. Kaplan-Meier 14-day probability of discontinuation from ventilation curve for patients with (blue) or without pendelluft (red) in the patients $\mathbf{A}$ with spontaneous breathing, $\mathbf{B}$ absence of spontaneous breathing, $\mathbf{C}$ spontaneous breathing and $\mathrm{P} / \mathrm{F}$ ratio below $200 \mathrm{mmHg}$ and $\mathbf{D}$ absence of spontaneous breathing and P/F ratio below $200 \mathrm{mmHg}$

\section{Acknowledgements}

\section{Not applicable.}

\section{Authors' contributions}

YC, $\mathrm{HH}$ and $\mathrm{YL}$ designed and planned the study. $\mathrm{YC}$ and $\mathrm{HH}$ were responsible for collection and assembly of data. YC, ZZ and HH was responsible for data analysis and interpretation. ZZ developed the software for the GI index and pendelluft analysis. YC, HH, ZZ, IF wrote the initial manuscript draft, and all authors were involved in critical revision of the final manuscript. All authors read and approved the final manuscript.

\section{Funding}

This study was supported by Capital's Funds for Health Improvement and Research (No. 2020-2-40111) and Excellence Program of Key Clinical Specialty of Beijing in 2020 for Critical Care Medicine, Beijing Municipal Science and Technology Commission (No. Z201100005520051).

\section{Availability of data and materials}

The datasets used or analyzed in the study are available from the corresponding author on reasonable request.

\section{Declarations}

\section{Ethics approval and consent to participate}

The ethics review board of Peking Union Medical Collage Hospital approved the study protocol. Informed consent was not applicable for the retrospective study.

\section{Consent for publication}

Not applicable.

\section{Competing interests}

The authors declare that they have no competing interests.

\section{Author details}

'State Key Laboratory of Complex Severe and Rare Disease, Department of Critical Care Medicine, Peking Union Medical College Hospital, Peking Union Medical College, Chinese Academy of Medical Sciences, 1 shuaifuyuan, Dongcheng District, Beijing, China. ${ }^{2}$ Department of Biomedical Engineering, Fourth Military Medical University, Xi'an, China. Institute of Technical Medicine, Furtwangen University, VS-Schwenningen, Germany. ${ }^{4}$ Department of Anesthesiology and Intensive Care Medicine, University Medical Center of Schleswig-Holstein Campus Kiel, Kiel, Germany.

\section{Received: 10 December 2021 Accepted: 11 February 2022} Published online: 05 March 2022

\section{References}

1. Harada K, Saoyama N, Izumi K, Hamaguchi N, Sasaki M, Inoue K. Experimental pendulum air in the flail chest. Jpn J Surg. 1983;13(3):219-26.

2. Vyshedskiy A, Murphy R. Pendelluft in chronic obstructive lung disease measured with lung sounds. Pulm Med. 2012;2012: 139395.

3. Yoshida T, Torsani V, Gomes S, De Santis RR, Beraldo MA, Costa EL, Tucci MR, Zin WA, Kavanagh BP, Amato MB. Spontaneous effort causes occult pendelluft during mechanical ventilation. Am J Respir Crit Care Med. 2013;188(12):1420-7

4. Yoshida T, Roldan R, Beraldo MA, Torsani V, Gomes S, De Santis RR, Costa EL, Tucci MR, Lima RG, Kavanagh BP, et al. Spontaneous effort during mechanical ventilation: maximal injury with less positive endexpiratory pressure. Crit Care Med. 2016;44(8):e678-688.

5. Morais CCA, Koyama Y, Yoshida T, Plens GM, Gomes S, Lima CAS, Ramos OPS, Pereira SM, Kawaguchi N, Yamamoto H, et al. High positive endexpiratory pressure renders spontaneous effort noninjurious. Am J Respir Crit Care Med. 2018;197(10):1285-96.

6. Yoshida T, Nakahashi S, Nakamura MAM, Koyama Y, Roldan R, Torsani V, De Santis RR, Gomes S, Uchiyama A, Amato MBP, et al. Volumecontrolled ventilation does not prevent injurious inflation during spontaneous effort. Am J Respir Crit Care Med. 2017;196(5):590-601.

7. Frerichs I, Amato MB, van Kaam AH, Tingay DG, Zhao Z, Grychtol B, Bodenstein M, Gagnon H, Böhm SH, Teschner E, et al. Chest electrical impedance tomography examination, data analysis, terminology, clinical use and recommendations: consensus statement of the TRanslational EIT developmeNt stuDy group. Thorax. 2017;72(1):83-93.

8. Coppadoro A, Grassi A, Giovannoni C, Rabboni F, Eronia N, Bronco A, Foti G, Fumagalli R, Bellani G. Occurrence of pendelluft under pressure support ventilation in patients who failed a spontaneous breathing trial: an observational study. Ann Intensive Care. 2020;10(1):39.

9. Sang L, Zhao Z, Yun PJ, Frerichs I, Möller K, Fu F, Liu X, Zhong N, Li Y. Qualitative and quantitative assessment of pendelluft: a simple method based on electrical impedance tomography. Ann Transl Med. 2020;8(19):1216

10. Sinha P, Calfee CS, Beitler JR, Soni N, Ho K, Matthay MA, Kallet RH. Physiologic analysis and clinical performance of the ventilatory ratio in acute respiratory distress syndrome. Am J Respir Crit Care Med. 2019;199(3):333-41.

11. Otis AB, McKerrow CB, Bartlett RA, Mead J, Mcllroy MB, Selver-Stone NJ, Radford EP Jr. Mechanical factors in distribution of pulmonary ventilation. J Appl Physiol. 1956;8(4):427-43.

12. He H, Chi Y, Long Y, Yuan S, Zhang R, Yang Y, Frerichs I, Möller K, Fu F, Zhao Z. Three broad classifications of acute respiratory failure etiologies based on regional ventilation and perfusion by electrical impedance tomography: a hypothesis-generating study. Ann Intensive Care. 2021;11(1):134.

13. Zhao Z, Möller K, Steinmann D, Frerichs I, Guttmann J. Evaluation of an electrical impedance tomography-based Global Inhomogeneity Index for pulmonary ventilation distribution. Intensive Care Med. 2009;35(11):1900-6.

14. Lopes FA, Souza LAM, Bernardi JTN, Rocha CE, Figueiredo LC, Agostini A, Dragosavac D, Faez D. Pendelluft diagnosed from ventilator weaning indexes obtained through bioelectrical impedance tomography: a case report. Sao Paulo Med J. 2017;135(3):302-8.

15. Rossi FS, Costa ELV, lope DDM, Pacce PH, Cestaro C, Braz LZ, Bousso A, Amato MB. Pendelluft detection using electrical impedance tomography in an infant. Keep those images in mind. Am J Respir Crit Care Med. 2019;200(11):1427-9.

16. Gonçalves-Ferri WA, Rossi FS, Costa ELV, Correa L, lope D, Pacce PD, Martins-Celini F, Bernardes A, Ribeiro M, Amato MBP. Lung recruitment and pendelluft resolution after less invasive surfactant administration in a preterm infant. Am J Respir Crit Care Med. 2020;202(5):766-9.

17. Enokidani Y, Uchiyama A, Yoshida T, Abe R, Yamashita T, Koyama Y, Fujino Y. Effects of ventilatory settings on pendelluft phenomenon during mechanical ventilation. Respir Care. 2021;66(1):1-10.

18. Pellegrini M, Hedenstierna G, Larsson AS, Perchiazzi G. Inspiratory efforts, positive end-expiratory pressure, and external resistances influence intraparenchymal gas redistribution in mechanically ventilated injured lungs. Front Physiol. 2020;11:618640.

19. Tulaimat A, Trick WE. DiapHRaGM: a mnemonic to describe the work of breathing in patients with respiratory failure. PLOS ONE. 2017;12(7) e0179641.

20. Apigo M, Schechtman J, Dhliwayo N, Al Tameemi M, Gazmuri RJ. Development of a work of breathing scale and monitoring need of intubation in COVID-19 pneumonia. Crit Care. 2020;24(1):477.

21. Borges JB, Morais CCA, Costa ELV. High PEEP may have reduced injurious transpulmonary pressure swings in the ROSE trial. Crit Care. 2019;23(1):404

22. Santini A, Mauri T, Dalla Corte F, Spinelli E, Pesenti A. Effects of inspiratory flow on lung stress, pendelluft, and ventilation heterogeneity in ARDS: a physiological study. Crit Care. 2019;23(1):369. 
23. Karsten J, Stueber T, Voigt N, Teschner E, Heinze H. Influence of different electrode belt positions on electrical impedance tomography imaging of regional ventilation: a prospective observational study. Crit Care. 2016;20:3.

24. Becher T, Bußmeyer M, Lautenschläger I, Schädler D, Weiler N, Frerichs I. Characteristic pattern of pleural effusion in electrical impedance tomography images of critically ill patients. Br J Anaesth. 2018;120(6):1219-28.

\section{Publisher's Note}

Springer Nature remains neutral with regard to jurisdictional claims in published maps and institutional affiliations.

\section{Submit your manuscript to a SpringerOpen ${ }^{\ominus}$ journal and benefit from:}

- Convenient online submission

- Rigorous peer review

- Open access: articles freely available online

- High visibility within the field

- Retaining the copyright to your article

Submit your next manuscript at $\boldsymbol{\nabla}$ springeropen.com 